\begin{tabular}{|c|c|}
\hline \multicolumn{2}{|r|}{ About the Journal } \\
\hline Journal DOI & https://doi.org/10.21659/rupkatha \\
\hline Journal Home & www.rupkatha.com $\searrow$ \\
\hline Indexed by & Scopus $\boldsymbol{\lambda}$ Web of Science: Emerging Sources Citation Index (ESCI) $\triangle$ DOAJ \\
\hline Journal Metrics & CiteScore 2020: 0.2 | SJR 2020: 0.162 | SNIP 2020: 0.193 | JCI 2020: 0.50 \\
\hline \multicolumn{2}{|r|}{ About the Issue } \\
\hline Themed issue & $\begin{array}{l}\text { Volume 4, number 1, } 2022 \text { (January-March) | Contemporary East and } \\
\text { Southeast Asian Literary and Cultural Studies }\end{array}$ \\
\hline Guest Editors & Dr Jeremy de Chavez $\triangle$ \& Dr Zhang Yue, University of Macau, China \\
\hline Issue DOI & https://doi.org/10.21659/rupkatha.v14n1 \\
\hline TOC & https://rupkatha.com/v14n1.php \\
\hline Peer Review & Under the responsibility of the Guest Editors \\
\hline \multicolumn{2}{|r|}{ About the Article } \\
\hline Title & $\begin{array}{l}\text { Translingual, Transcultural, and Transboundary Sceneries: Aesthetic Ideas } \\
\text { and Discursive Practice in Yu Dafu's Landscape Writing }\end{array}$ \\
\hline Author/s & Yidan Wang $\otimes$ \\
\hline Affiliation & Duke University \\
\hline Funding & No funding received. Published free of any charge. \\
\hline Article DOI & https://doi.org/10.21659/rupkatha.v14n1.05 Pages: 1-17 \\
\hline Abstract & https://rupkatha.com/v14n105 \\
\hline Full-text PDF & https://rupkatha.com/V14/n1/v14n105.pdf \\
\hline \multirow[t]{3}{*}{ Article History } & Abstract received: 31 March 2021 | Complete article received: 2 June 2021 \\
\hline & Revised article received: 5 Dec 2021 | Accepted: 16 Dec 2021 \\
\hline & First Published: 05 February 2022 \\
\hline Article Impact & Check Dynamic Impact $\triangle$ \\
\hline Copyright & Aesthetics Media Services $\square$ \\
\hline Licensing & Creative Commons Attribution Non-Commercial 4.0 \\
\hline
\end{tabular}

This Open Access article is published under a Creative Commons Attribution Non-Commercial 4.0 International License (http://creativecommons.org/licenses/by-nc/4.0/), which permits non-commercial re-use, distribution, and reproduction in any medium, provided the original work is properly cited. For citation use the DOI. For commercial re-use, please contact editor@rupkatha.com. 
1 Rupkatha Journal, Vol. 14, No. 1, 2022

Research Article

\title{
Translingual, Transcultural, and Transboundary Sceneries: Aesthetic Ideas and Discursive Practice in Yu Dafu's Landscape Writing
}

\author{
Yidan Wang \\ Duke University
}

\begin{abstract}
The ways in which nature is watched and represented have changed rapidly alongside modernization in 20th-century China. This can be regarded as the product of an epistemological transformation led by the encounter of Chinese and Western cultures. One of the representatives in this transformation and fusion of seeing is Yu Dafu, who, although generally known for his fiction, penned many travel writings and descriptions of nature in the 1930s. Regarding Yu's travelogue as an embodiment of his translingual and transcultural reflections, this paper reviews previous studies on Yu's travelogue and investigates its latent creativity and antinomy. This article delves into the stylistic and aesthetic features of Yu's travelogue to uncover the conservatism and misogyny obscured beneath the seemingly value-neutral landscapes, arguing that Yu's travelogue is a twofold amalgamation of genres and aesthetics. On the one hand, his travel writing is an adaption and combination of the German Baedeker guidebooks and traditional Chinese travel notes (Youji 遊記). On the other hand, Yu's texts incorporate aesthetic criteria influenced by different natural concepts, demonstrating both his broad vision ahead of time and his conservatism. Yu's writing on nature and landscapes, as a discursive practice motivated by the emergence of tourism in his era, is a transboundary dialogue between literature and commerce, and the elite and the general public, while also implicitly denying the common people access to the scenery space. Through a close reading of Yu's frequently employed tropes-picturesque and feminized scenes-I establish an isomorphic relationship between his views on nature, art, and female. Finally, the antinomy inherent in Yu's landscape imaginary constructed by creativity and conservatism points to the ambiguity of the New Culture.
\end{abstract}

Keywords: modern Chinese literature, landscape, space, travel writing, cross-cultural communication.

\section{Introduction}

In European art history, the role of the landscape changed after the Renaissance to become an artistic theme in its own right, rather than a background for religious or mythical works. (Andrews, 1999, pp. 1-51). In Chinese culture, the landscape as an artistic theme emerged much earlierlandscape poems (Shanshui poems) appeared in the 4th century, ${ }^{i}$ and landscape paintings (Shanshui paintings) emerged in the 5th (Sullivan, 2008). The paradigm of nature and its means of reproduction, however, changed rapidly in the $19^{\text {th }}$ and $20^{\text {th }}$ centuries. Kojin Karatani (1993) compares "landscape" to an "epistemological constellation" (p.22) between Asian and Western cultures and builds an isomorphic relationship between modern landscape and literature in his discussions of literary realism in 1890s Japan. Western epistemological elements, especially the 
laws of perspective, stripped away the transcendental conception in traditional scenes and transformed the landscape from signifier to signified. "i According to Karatani's investigation of Japanese literature, Wu (2017) explains the importance of Yu Dafu's (1896-1945) travel writings in the construction of the modern Chinese landscape and puts these articles in a context of consumerism.

One of the most important writers of the New Culture Movement (Xin wenhua yundong) in the 1910s-40s, Yu Dafu was well-known for his stories Sinking 沉淪 (1921) and Intoxicating Spring Nights 春風沈醉的晚上 (1924), which are regarded as representative works of New Literature. Such achievements established Yu's literary reputation and social influence, and he was invited to write propaganda for local tourist attractions. He consequently turned his attention from fiction to travel writing in the 1930s.

Based on Jiang's (1996) and Wu's (2012; 2017) discussions of Yu's collaboration with authorities and commercial powers in his travelogues, this article will examine the stylistic characteristics induced by the new sponsor and mechanism of writing, as well as the aesthetics inherent in these works, which contribute to a new imaginary of nature in modern China. In contrast to Wu's $(2012 ; 2017)$ assertion that Yu's travelogues are the product of Western cultural dominance, I would argue that these works demonstrate Yu's decreasing reliance on Western resources and increasing confidence in classical Chinese, which reflects a shift in Yu's language model underlying landscape presentation.iii

Throughout this paper, "landscape" corresponds to Karatani's (1993) definition mentioned above, which refers to both physical sceneries observed by a subject and literary space to describe them, and thus embodies epistemic modalities of a modern subject. Writers like Yu tried to create a novel experience of nature through their writings in the nascent vernacular Chinese. Except for the introduction, this paper has been divided into four parts. The first gives a brief overview of Yu's personal working history and its relationship with other aspects of his life. The importance of official patrons, Chinese Youji, and German travel guides to the shift in his literary interest will be discussed. The second and third parts outline two major aesthetic models in Yu's nature writing: picturesque and feminized landscapes. The two patterns will be investigated in diverse contexts, including Chinese classic and English literature, art history, and gender issues. In the fourth, I reflect and draw conclusions on the biases and stereotypes of nature, gender and culture, and discuss conservatism behind these preconceptions.

\section{Travel Writing Motivated by New Patrons and the German Guidebook Genre}

Though famous for his fiction, Yu increasingly turned to travel writing in the 1930s. Facilitated by the development of transportation and tourism in China during this period, Yu participated in multiple official travel activities and often wrote prose at the request of the railway bureau and the local government. ${ }^{\text {iv }}$

Yu names these works as Youji 遊記, which roughly corresponds to travel writing/literature in English. Both of the Chinese and English phrases, however, are umbrella terms encompassing 
diverse branches. In English, according to OED, "travel writing" refers to "a genre of writing in which authors describe places they have visited and their experiences while travelling." ${ }^{\prime \prime}$ In Chinese, the authoritative dictionary Comprehensive Chinese Word Dictionary 漢語大詞典 defines Youji as a genre recording travel experiences, ${ }^{\text {vi }}$ while literary scholars in ancient Chinese studies are divided on the concept of Youjirii. In this paper, I examine Yu's travel writing from the 1930s to the 1940s and argue that it is a hybrid of traditional Chinese Youji and German Baedeker, serving as both an account of Yu's outdoor voyage in nature and a commercial guide. Although there is a long history of travel literature in China, viii Yu's work displays new features influenced by traditions from world literature. Such innovation fueled a renewal of Chinese travel writing and explored the possibility of cooperation between literature and its patrons.

One reason for Yu's transition to travel writing was that he had hit a creative block. Between 1928 and 1945, his output of fiction declined and ultimately ceased, while his production of travelogues simultaneously increased. ${ }^{i x}$ In 1928, Yu travelled around Wuxi and Yangzhou to avoid arrest by the authorities for political reasons. During this trip, he wrote $A$ Sentimental Journey 感傷的行旅, which still assembles to his former styles in travel accounts in An Account on the Smoke and Rain of Suzhou 蘇州煙雨記 (1923), expressing intense personal emotions and psychological activities but hardly including dialogues with or guidance to the readers. In 1933, Yu moved with his family from Shanghai to Hangzhou, from where he travelled through sixty to seventy per cent of Zhejiang Province and wrote works such as Records of a Brief Journey to Hangjiang (Hangjiang Xiaoli Jicheng). In 1936, Yu moved to Fuzhou, where he worked as an official in the local department of culture. During this period, Yu wrote six pieces of prose in the series of The Trifles of Fuzhou Journey 閩遊滴源 (1936), which introduced local views and cultures to northerners. In 1938, while on the way to Singapore, he wrote Travel Notes in Malacca 麻六甲遊 記 (1940). Towards the end of his life, he travelled to Indonesia, where he was killed by Japanese soldiers in 1945.

As a pioneer in New Literature, Yu Dafu unusually looked for inspiration from traditional documents in his travel writing. Yu cited plenty of historical records in these articles and was keen to check the accuracy of obscure books, which were sometimes unknown to the public. Yu himself and almost all researchers therefore directly refer to these travel texts as examples of the traditional Chinese genre Youji (travel notes). Hong (2006) present Yu's turn away from fiction and embrace of Youji as "a return to the world of traditional Chinese scholar-officials (Shidafu)" at a low point in his life (p. 702). However, as Wu (2012) proposes, in the context of the post-1920 development of Chinese travelogues, tourism and transportation, as well as the details featured in Yu's prose, Yu did not simply abandon modern literature and run back to tradition. Although there are similarities between Yu's travelogues and traditional Youji, his work is a product of influences from Western literature and the emergence of a new kind of patron. On the one hand, Yu's travel writing retains the same keen interest in Western literature as his early short tales with notable quotations, which I will explore further in the next section. Yu's travelogues, on the other hand, imply a conscious contemplation and introduction of the German genre Baedeker. In his first travelogue, Yu regards his work as a modification of traditional Baedeker guides:

"Days before, Zeng Yinqian, the director of Hangjiang railway traffic, asked a friend to invite me to travel around the East of Zhejiang Province. They requested that I write about 
4 Translingual, Transcultural, and Transboundary Sceneries: Aesthetic Ideas and Discursive Practice in Yu Dafu's Landscape Writing

the scenery along the way, and introduce it to Chinese and foreign travellers. The railway from Hangzhou to Yushan has been finished and should be open to the public at the end of December. At the same time, the railway bureau hopes to collect my Youji in their forthcoming guidebooks, which would alleviate and balance the vacuity and boredom of Baedeker guides" [emphasis added]. (Yu, 2007, Vol. 4, p. 35)

The Baedeker guides that $\mathrm{Yu}$ refers to are travel guides named after German publisher Karl Baedeker (1801-1859). The first, Rheinreise (Rhein trip) was published in 1828, and later many other Baedekers were published, revised, and translated into French and English. They spread widely across Europe and became established as a new genre conditioned by tourism and publishing. A standard Baedeker usually provided an index of local information on, for example, accommodation, transportation, travel routes, and sightseeing. In this light, Yu's citation of Baedeker suggests his knowledge and reflection of this German genre.

With the growth of tourism, editors and the market placed new demands on travelogue authors. In a retrospective commemorating the tenth anniversary of China Trave/ 旅行雜誌, ${ }^{x i}$ editor Zhao Junhao (1936) outlined the following standards for manuscripts:

"While a travel writer must know how to write, draw, and shoot, it is more necessary to know how to guide subsequent travellers... We have received many travelogues that simply show the natural beauty and challenges of the voyage while forgetting the most important function of Youji [travel notes], which is to guide other travellers. Few writers are able to keep up with the demand. What a shame! "

Despite sharing the same name, Zhao's essay explicitly distinguishes between traditional Youji and modern travelogues. Readers and editors from ancient China will not consider travel instruction to be a necessary component of Youji, because long-distance travel is difficult, and the experience they seek from the text is more akin to "recumbent travel" (臥遊). However, Zhao's article implies that readers' demands had altered as a result of tourism and that most of the travel notes were unable to meet them. Yu's travel writing is valuable in this regard, given it consciously "guides" the reader, implying his awareness of the new expectation from readers.

Yu's literary awareness stems from his extensive reading of Western works, particularly Baedeker, which he mentions. As stated, Yu disliked Baedekers because he found them boring. This criticism reflects his awareness of the links between Baedekers and his own writing, which was an endeavour to modify the Western genre. At the same time as he expressed his intention to "alleviate and balance the vacuity and boredom of Baedeker guides," he introduced this new genre to the Chinese leadership. The Scene in the East of Zhengjiang (浙東景物紀 Zhedong Jingwu Ji), from which the preceding quote was taken, was part of the Guidebook Series published by the Hangjiang Railway Bureau. This volume includes photographs and maps, and also lists railway stations and accommodation (see Figs. $1 \& 2$ ), bestowing its practical value on travel. Furthermore, The Scene in the East of Zhengjiang is a collective effort including other writers' articles besides Yu's, similar to Baedeker, which normally invites specialists to gather information and give modifications (Mendelson 1985). These features effectively differentiate the book from conventional Youji and transform it into a Chinese Baedeker. In a larger context, The Scene in the 
East of Zhengjiang embodies a period in which the Chinese Baedeker began to thrive. More than 400 Chinese Baedeker guides were written between 1912 and 1937 when China's transportation infrastructure was upgraded and its mass tourism industry began to develop (Zhao, 2017). light, even though Yu publicly rebuked Baedekers, he yet contributed to the publishing industry by default, given that his stellar literary reputation is the best advocation of the scenic spots and the genre in general.

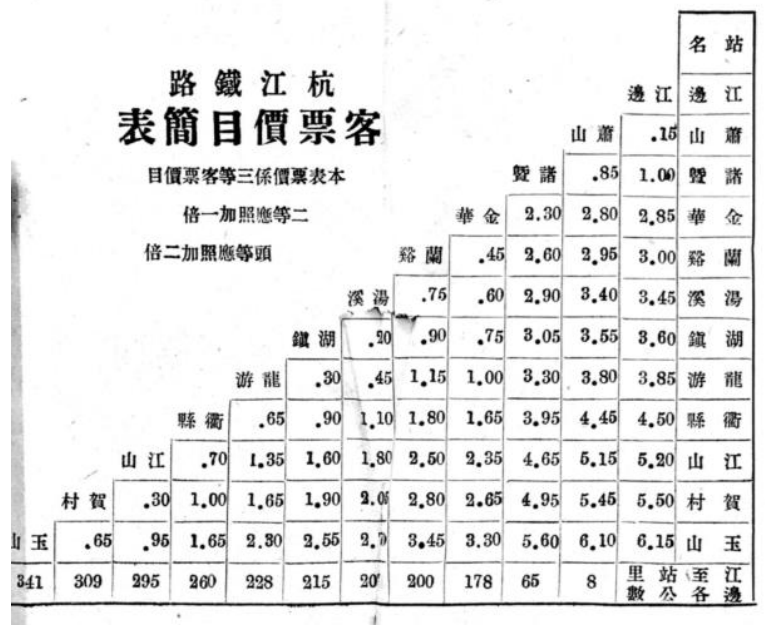

Figure 1: Hangjiang Railway Fare Table, The Scene in the East of Zhengjiang, 1933, p. 161.

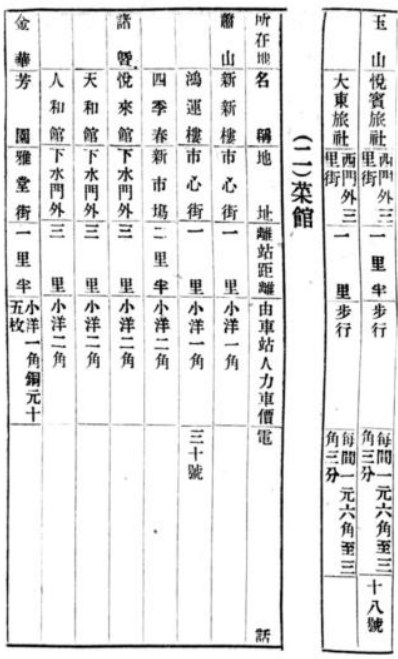

(141)

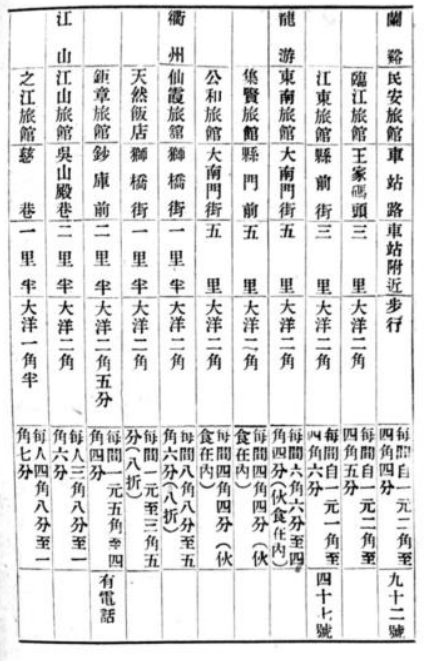

(140)

Figure 2: Information on Local Accommodation, The Scene in the East of Zhengjiang, 1933, pp. 140-1.

Yu took aim at Baedeker again in his travelogue Hangzhou, which was published in 1934. After introducing the city's citizens, customs, history, natural scenery and suburbs, he states: "My description will not discuss the daily life and diet in Hangzhou, since I do not write tour guides of West Lake [emphasis added]" (Yu, 2007, Vol. 4, p. 93). In issuing this dismissive observation, Yu 
sought to establish distance between his works and the Baedeker guidebooks. In doing so, however, he inadvertently reiterated the considerable amount that they had in common. The lines between them are pretty blurred. Yu's self-contradiction raises the question of precisely what he hoped to achieve by drawing this distinction repeatedly.

The answer can be traced back to the character of the Baedekers. Their rapid spread from Germany to France and then to England can be attributed to their standardized mode of production. On the one hand, they formulaically listed essential information about a place, removed the editor's personality from the text and presented each book in a uniform style. After the 1890s, "the handbooks' prose grew more efficient and compressed," as Mendelson (1985) elaborates, and "Baedeker used the parenthesis most often as a rapid indicator of the quality of hotels and restaurants." That explains why Yu criticized Baedeker as "boring." On the other, Baedekers were typically anonymous or signed in the (symbolic) name of Karl Baedeker. In 1913, for example, Northern Italy was published by the Baedeker Company under the name of Karl Baedeker, in apparent ignorance of the fact he had died in 1859. This attested to the fact that Baedekers had no real interest in the author or editor, which elicited consternation from $\mathrm{Yu}$, who expressed his concern that they presaged "the death of the author." xiii

Yu overcame his fears by using resources from the traditional genre Youji. After accepting the Hangjiang Railway Bureau's invitation, he wrote a series of articles that advertised the scenery along the newly-built railway. These articles portray the author's experience in detail, simultaneously give geographic information from historical records and are adorned with diverse literary quotations and legends. The itinerary Yu provided for travellers is usually based on his journeys, and the quotations depend on his reading preferences. These approaches from Youji give Yu's guidance unique personalities, which differentiate his articles from the Baedekers. In contrast to Baedeker, Youji is characterized by individuality, lyricism and a disregard for practical information about places. ${ }^{\text {xiv }}$ As Tian (2011) comments, Chinese travelogues display their strong personalities from their very beginnings:

"Rather than impersonally cataloguing local sites, products, and customs, many of these new travel accounts record personal experiences during these journeys. Crystallized in first-person anecdotes as well as in descriptions of movement through specific places at specific times, the individualized element of these travel writings does not aspire to give an "objective" account of what there is to note, but rather presents the world as seen through the eyes of a historical subject, an individual person." (p. 3)

Influenced by the requirements of tourism, Yu's travelogues catalogue "local sites, products, and customs" from an "objective" perspective, which makes them different from traditional Youji. On the other hand, he employs Youji approaches to counter-balance the commercial character and openness of the Baedekers. In doing so, he reasserts the literary character and authorship of his writing. This insistence on individuality in guidebooks can perhaps be better explained by referring to $A$ Guide of the Lakes by Wordsworth, a poet whom Yu deeply admired, and who makes frequent appearances in his work. At the beginning of $A$ Guide, Wordsworth (1835) comments: 
"It was the Author's principal wish to furnish a Guide or Companion for the Minds of Persons of taste, and feeling for Landscape. [For] the more sure attainment, however, of this primary object, he will begin by undertaking the humble and tedious task." (p. i)

Wordsworth therefore posits a dialectical relation between aesthetic pursuit and writing practice in the production of a new landscape. Both Wordsworth and Yu anticipate and sustain their assertion of the author's subjective consciousness in their travel guides.

Moreover, Yu's grasp of genre dates back to his early work. Wang (2021) explores how Wordsworth's poem The Solitary Reaper inspired the environmental background and narrative structure of Sinking, demonstrating the novella's genre complexity. Contrary to Wang's assertion that Yu ceased writing fiction that embodies various genres following Sinking, Yu's reflections and experiments with Youji and Baedeker in travelogues indicate his continued interest and selfconsciousness of the literary genre.

In addition to adopting an increasingly stylized approach to travel writing, Yu's reading materials during his journey were also beginning to change subtly. Yu's early writings, as compared to travel notes from the 1930s, mention Western literature far more frequently than Chinese novels when depicting nature. In $A$ Sentimental Journey (1928), when Yu visits the ancient Chinese cities of Wuxi and Yangzhou, he advises his readers to bring a "German travel book" (Yu, 2007, Vol. 4, p. 4), which also demonstrates that Yu reads Baedeker often. In his earlier short story Sinking, the hero, on being confronted by wild Japanese scenery, oddly quotes a Wordsworth poem about the British landscape to express his feelings (Yu, Vol. 1, pp. 39-75). As Wang (2021) examines, Wordsworth's poem The Solitary Reaper is critical to the natural setting and narrative construction of Sinking. Additionally, as Lee (2006) elaborates, Yu's another early novella, Journey South 南遷 (1921), incorporates German Romanticism into its structure. Confronted with the picturesque coastline of a Southern Japanese island, the characters sing and discuss Goethe's Mignon, a song from the novel Wilhelm Meister's Apprenticeship. These early writings before the 1930s demonstrate an odd correspondence between the physical environment and its linguistic portrayal.

In contrast, Yu's later travel guide writings from the 1930s draw on a diverse range of history books, maps and local products, and air concerns from public perspectives. Yu's diaries in Fuzhou, for example, show that he did not begin his travel writing until after collecting and reading books that included Fujian Poems, General Chorography of Fujian, Records of the Products in Fujian, and Wuyi Chorography. The majority of these texts are historical and geographical literature, or poems by unknown poets, which defy the literary criteria Yu and other intellectuals upheld and turn Yu's reading and quoting into a form of textual discovery. Yu's discovery of local documents closely is his preparatory collection work for the Baedeker edition and embodies his personal history of reading.

Yu's trust in classical Chinese represents a shift in his language ideal. As Levan (2012) examines, in Yu's early short stories, classical Chinese is "imagined as linked directly" to the experience; in contrast, foreign literature is viewed as the ideal vehicle for expressing contemporary experience, in which linguistic vision reflects the semantic predicament $\mathrm{Yu}$ and many other intellectuals met in the transitional period. However, in Yu's 1930s travelogues, Western quotations gradually decrease, while classical Chinese references become increasingly 
important. This is not a straightforward return to pre-modern Chinese, but rather a departure from Yu's earlier linguistic model. In this sense, Yu's use of ancient literature re-establishes a connection between classical Chinese and contemporary experience, and it is through travel that Yu discovers the significance of Chinese history's overlooked texts. ${ }^{\mathrm{xv}}$ Ancient books, in this light, not only guide Yu to new spots but also point to a new way of experiencing and representing the world, causing a vibration of a linguistic and epistemological shift and partially resolving the semantic conundrums in modern vernacular Chinese literature that Levan (2012) mentions.

The personalities of these travel writings stretch them beyond commercial incentives and integrate Yu's desire to learn about and engage with the world at a time when his literary career was stagnating. This gives Yu's travel writings a dual nature. Because they render an intense consciousness of authorship, his Baedeker writings do not simply list local information, but also encapsulate his aesthetic ideal; and because Baedekers were produced to speak to the public, Yu's travel writings do not simply express his personal views and sentiments. In general terms, these writings reflect his interpretation of the public interest and also represent an attempt to engage the public in dialogue. The transformation of the relationship between reading and practice eventually influenced Yu's other travel accounts that were written without the support of a patron. Over time, the outside incentives from patrons and tourism were internalized, and in the end, contributed to a paradigm shift in how people understand and write about nature.

\section{An Ideal Model of Nature: The Picturesque Landscape}

In the tropes Yu used to describe the landscape, his ideal scenery can be divided into two aesthetic patterns: picturesque and feminine. Yu's travel texts usually employ the tropes of paintings and females to extend beyond simply stating facts and listing information. As a consequence, the subject comes to appreciate the landscape in the same way he/she appreciates a piece of art and/or a woman.

Yu's landscape, as Wu (2012) investigates, illustrates a preference for comparing natural scenes to Western paintings. In his early works, like Sinking and Journey South, Yu shows a keen interest in nature. Yet discussions about these works often overlook the fact that descriptions of landscape in prose, rather than in verse, was not prevalent in fiction until the New Literature Movement. In other words, the origins of the prosaic landscape in fiction are interwoven with new literature (Nakazatomi, 2017). Apart from introducing Western Romanticism (Lee, 2006), the trope of Western paintings implies Yu's peculiar perspective in viewing and writing about the scenery. Sinking praises a beautiful view of a Japanese field as being "like a picture" (Yu, 2007, Vol. 1, p. 61), compares the view from a mountain to "Millet's pastoral landscape paintings" (p. 65), and renders scenery as a picture revealed by God, which compels the narrator to feel compassionate and tolerant towards the world.

This picturesque view of the landscape is also reflected in Yu's travel writings. Upon being confronted by the landscape in Zhuji, a small town in Zhejiang Province, Yu was reminded of illustrations of the Rhine and Danube rivers, and Heine's poem Die Lorelei, which he had read in a textbook (Yu, Vol. 4, pp. 35-53); upon witnessing the glaciers in Yuchuan, he claimed: "With 
mountains and water, along with a water wheel, a mill, a fishing dam, a stone cliff, a water gate, and a causeway, everything necessary to decorate the scenery in a Chinese painting or watercolor is present" (pp. 54-68). He also likens the landscape of Mount Tianmu to "extremely dedicated traditional Chinese Fine Brushwork" (pp. 69-87) and a "Green Shanshurvi painting by Li Zhaodao" (pp. 69-87). Such vivid imagery, which compares the scenes to paintings, recurs dozens of times in his travel writings.

This raises the question of what exactly Yu was trying to present when he compared a landscape to a painting. He described Tianmu Falls, for instance, as "indeed a fine view, like a picture." What kind of scenery can be read as "a picture?" Yu himself never defined the standards of the picturesque, but in his texts, the word "picturesque" undoubtedly represents the beauty of nature and expresses the pleasure of the beholder. According to the examples above, Yu's picturesque standard generally derives from two broad painting styles: pictures with western techniques and Chinese Shanshui paintings.

As previously stated, Yu's changing emphasis on different resources reflects his shifting language ideal. In this sense, I would argue that Yu's citations of western paintings are not simply "borrowing" Western values to signify indigenous nature or producing simulacra of Western sights (Wu, 2012), but rather an attempt to remake a modern language through cultural blending, which, as Levan (2012) elaborates, is motivated by cosmopolitanism rather than Eurocentrism. The increased use of traditional Chinese texts in his travelogues signifies Yu's growing confidence in the classical language as a means of expressing modern experiences. xvii What lies underlying Yu's varied references is rather an ideal vision that transcends existing cultural schemata. When $\mathrm{Yu}$ stands in front of Dalongqiu Fall, he feels as if the surrounding inscriptions, the works of ancient literati collected in the local gazetteer, and even his prose are dwarfed by the "true view." (The Autumn Moon over Mount Yandang, pp. 147-8). Additionally, Yu considers the best artworks per se to be a part of "nature:"

Wordsworth's natural poetry, Millet's pastoral paintings, and Beethoven's stormy music are all facets of nature, which is completely ingenious and devoid of any hypocrisy $(\mathrm{Yu}, 2007$, Vol. 10, p. 58)

In this sense, the analogies between the immediate and referential scene indicate the asymmetry between language and reality, as well as the distance between the subject and nature, which finally constructs an aura of the landscape. If the Western painting symbolizes the spatial distance between scenery and picture, the model of Shanshui can be said to illustrate temporal distance. Indeed, as W. J. T. Mitchell (2002) observes, distance is a prerequisite in a landscape:

"The landscape imperative ["Look at the view!"] is a kind of mandate to withdraw, to draw out by drawing back from a site. If a landscape, as we say, 'draws us in' with its seductive beauty, this movement is inseparable from a retreat to a broader, safer perspective, an aestheticizing distance, a kind of resistance to whatever practical or moral claim the scene might make on us." (p. viii)

On the other hand, as Wu (2012) points out, Yu's transcendental ideal can distort reality in ways other than through imitation of Western arts. In Yu's picturesque perspective, the beholder experiences reality through pre-existent conceptions, and the ideal picture form becomes the 
criteria by which reality is evaluated. The precise meaning of a "good view" is already determined before the observer settles his/her gaze in nature. The supposed "discovery" of the landscape could, therefore, to some extent, be better described as verification of prejudgments. When appraised through the picturesque gaze, the scenery that is worth describing must match the transcendental aesthetic form. The real scene must consequently be modified and reconstructed if it is to be a qualified object of appreciation. Yu provides an example of this when he suggests how a view of Tiantai Mountain should be modified to meet a picturesque standard. He comments:

"The eaves of the Tanhua Kiosk in the Middle Fangguang Temple that extrude from the forest above the fall are neither exquisite nor ethereal. But if someone were to slightly modify the roof angle and add some red and yellow paint to the scenery, it would be an unparalleled picture." (Yu, 2007, Vol. 4, p. 135)

Though the picturesque ideal seems to resonate well with Yu's landscape writing, a tension remains between this ideal and the demands of tourism. It has already been observed that Yu's travel writing is not simply an individual record but also aspires to emulate Baedeker, and therefore seeks to enhance the understanding of the most general readers. The landscape that $\mathrm{Yu}$ constructs should therefore be universally accessible to the public. The picturesque aesthetic in Yu's articles, however, imposes highly cultural demands on readers. Yu himself was aware of this incongruity. After eulogizing the sights in Xixi, he observes:

"Indeed, the scenery in Huawu, especially in places like Qiuxue Nunnery and Jiaolu Nunnery, is elegant and tranquil. Those without a knowledge of the Southern School of Painting or Wang Wei and Wei Yingwu's poetry will, however, draw a blank in these places." (Yu, 2007, Vol. 4, p. 93)

The Southern School arose and the two poets lived both in Tang Dynasty (618-907). In Yu's opinion, an eligible viewer of the picturesque landscape must paint a natural picture in his/her brain, by drawing on literary and artistic scholarship. As a discursive practice, Yu's construction of natural space, therefore, excludes the masses who lack education about traditional culture. Even if they physically visit these places, they will be aesthetically rejected by the landscape.

From this perspective, there exists a contradiction between the accessibility of these emerging tourist attractions and the latent isolationism of the knowledge hierarchy. In this way, Yu's descriptions of nature became the fulfilment of cultural orders, which may have challenged those patrons who wished to attract more tourists, as well as Yu's 1928 advocacy for the massification of literature and art, claiming that good work should be "[b]y the people, for the people, and of the people" (Yu, 2007, Vol. 10, p. 450). These contradictions result from the integration of genres and artistic concepts in Chinese and Western cultures. Yu's genre is balanced between Baedeker and Youji, and the archetype of his picturesque scenery combines his artistic imagination with traditional Chinese aesthetics in Shanshui paintings and poetry, Western books and arts, and European sites he had never visited, which sometimes existed for him as landscape paintings rather than reality.

\section{The Feminized Landscape and the Landscaped Female}


Another ideal model Yu constructed in his guides was the feminized landscape. As Wang (2021) argues, in Sinking, nature is synonymous with women and religion to the protagonist, and the relationship between nature and reality indicates a struggle between spirit and flesh. In a subsequent short story titled Sunset 落日 (1923), Yu paints the sunlit autumn sky as bright as "a virgin's eyes" (Vol. 1, 297), also reinforcing the connection between nature and females.

Yu's travelogues from the 1930s take this symbolic imagining of nature a step further, crystallizing the illusion about women through races and personalities. In his landscape writing, nature automatically takes on female characteristics, and different types of scenery are anthropomorphized as different kinds of women. For instance, Yu describes Qingdao "as like a lady from a well-bred family. If the city has her nationality, she is a beautiful woman from southern Europe, satisfying her lust and hiding her real identity" [emphasis added] (Journey to Qingdao, Jinan, Beiping, and Beidaihe, Vol. 4, p. 151). Here, a woman's noble identity contrasts with her lust. If she does not wish to behave well as "a lady," then she should hide her nobility.

In Yu's imagining, the greatest tribute that can be paid to a female landscape is giving it the characteristics of purity and passivity. This sort of nature is obliged to have few artificial decorations or modifications, and it should always be open to the sight of male beholders, in the expectation it will be discovered and possessed by them. In instances where the landscape fell short of such expectations, Yu deployed vicious tropes. His strong dislike of Hangzhou, for example, led him to compare its landscape to a woman wearing heavy make-up. He observes:

"It has been said the character flaws of Hangzhou people are to be blamed for the overbeautiful sceneries. The West Lake in Hangzhou is like a fox spirit, in the shape of a young beauty with a soft and charming body. They say this is why Hangzhou can never cultivate good men. Well this opinion, to some extent, holds water" [emphasis added]. (Yu, 2007, Vol. 4, p. 91)

Yu's simile comparing an evil place with a bad woman is a tacit admission of the similarities between a location and a woman. The comparability derives from their common status as objects. In Chinese mythology, the fox spirit (hulijing) can acquire human forms. It usually metamorphoses as a beauty, tempts men to indulge their feelings of lust, and finally murders them. In daily discourse, the fox spirit is usually used as a metonym of a gorgeous but evil female. As Lu Xun (1918) criticizes, the emphasis on female chastity is a Confucian legacy; whereas the femme fatale, as McLaren (1994) states, signifies "a counter-model to the Neo-Confucian paragon of passivity and submission" (p. 2). For Confucian moralists, glamorous women who tempt men are considered hazardous and immoral. In presenting the scenery as a she-devil, Yu made an oblique reference to the idiom that a femme fatale is "one who devastates city and state" (qing cheng qing guo) ${ }^{\text {xiii }}$ and thus added an ethical filter to a landscape he already despised. Indeed, such a perspective perpetuates Yu's intrinsic misogyny in his literary works. As Xu (2009) illustrates, female characters in Yu's fiction are always portrayed as non-human and devoid of free will. Earlier in 1916, in a letter to Chen Bicen, Yu described "women in the world" as "the embodiment of demons" and vowed to stay away from them for the rest of his life (Vol. 6, 10). Following his second marriage, Yu depicts females with even greater hostility and viler curses in his fiction The Stray Lamb 迷羊 (1927) and She Is a Weak Woman 她是一個弱女子 (1932), in which women with uncontrollable sexual desire induce men's impotence (Xu 2009). Additionally, Yu repeats the "four main stages" of traditional 
femme fatale plot structure proposed by McLaren (1994, pp.12-3) in She Is a Weak Woman, emphasizing the retribution and calamity that is symbolized by the Japanese army's rape and murder of the heroine, Zheng Xiuyue. In this regard, Lu Xun's and Yu Dafu's diametrically opposed attitudes toward virginity exemplify Hong's argument that Yu's creations lack a true sense of modern consciousness while embodying the perception of contemporaneity (p. 689).

In Yu's travel writing in the 1930s, the landscape and women are conjoined in an isostructural chain through analogies. Yu's prose implies that both should embody an aesthetic ideal-they should be gentle, quiet, and stripped of their desires. His description of Huawu, a place that had particularly impressed him ten years prior, is typical in this regard. He writes:

"If I shall compare Huawu to a person, it is like the wife of a Xunyang merchant who plays the lute alone. ${ }^{\text {ix }}$ If I shall compare Huawu to a flower, it is like a peach, which has faded after its blossom and awaits the spring. If I shall compare Huawu to a dish, it is made of mushroom and tofu, light but tasty." (Yu, 2007, Vol. 4, p. 161)

In Yu's memory, Huawu is a delightful spot because it is simple and elegant, like a married middleaged woman whose libido declines, or a fragrant dish that lacks rich flavor. Nevertheless, to Yu's surprise, Huawu had been transformed by tourism and transportation and had become more commercial and crowded by the time he visited again. This change irritated $\mathrm{Yu}$, and he described the effects of commercialization on the town as "an unadorned and naïve, sedate and demure young girl, suddenly raped and abandoned by a wealthy man" (Yu, 2007, Vol. 4, p. 163). Yu criticized these social changes through the phenomenon we now call slut-shaming, and he transplants Freud's (2001, pp. 179-190) Madonna-whore complex into nature.

Contrary to the hateful landscape described as femme fatale or raped females, $\mathrm{Yu}$ imagined the beautiful scenery (or woman) as a Madonna-like redeemer of existential crisis. By this logic, Yu's landscape is a place of rehabilitation, ${ }^{x x}$ an antidote to urban diseases or the darkness of human nature, ${ }^{x x i}$ and even a site where life ends in death. Such views of nature and females also appear in Yu's work before his travel writing. In the story Smoke Shadows (煙影) (1926), he states: "For Zeng Pu, life or death is not a big deal. But since one is doomed to die, he hopes to die in a beauty's arms, or at least to die in the ocean waves on a calm night, alongside the moon and wind" (Yu, 2007, Vol. 1, pp. 401-2). Remarkably, this expression restricts beautiful women and landscapes to an abstract model and purpose by imaging them as ideal life destinations. In this manner, both nature and female lose their power and become passive recipients of the male gaze.

Based on the observations above, Yu's female landscape embodies a gaze imbued with male desire and traditional ethical restraints, which require female compliance in issues of sexual politics. The model of the female landscape implies a mirrored relationship between women and nature: the female is objectified to describe an ideal landscape, in which process she is also watched as one. Nature is thus refracted through the female body and presented as a landscape.

The virginal and picturesque ideals are not unique in Yu's descriptions of landscapesthey can also be found in his fiction. Further, the two models are interconnected when Yu employs a picturesque perspective to evaluate the landscaped woman: 
"Miss $\mathrm{K}$ was sixteen years old, with the beautiful face of a chaste virgin, wearing the black uniform of a medical school for girls. When Zhifu met her, she reminded him of the icon paintings of the Renaissance" [emphasis added]. (Yu, 2007, Vol. 1, p. 193)

Here, the subject of the icon should be Madonna. Yu reiterates the virginal perspective, as he does in his descriptions of landscapes, and invokes the virgin by referring to "icon paintings." In this trope, he employs the ethical schema of Christianity to female morality and behaviour. Another example is provided in Yu's novella The Stray Lamb, in which he describes the beautiful heroine as the kind of lady he "has only seen once or twice, in French albums" (Yu, 2007, Vol. 2, p. 119). Again, like in his observations of the landscape, the association between beauty and albums establishes a clear parallel between watching a woman and looking at a picture. Here, the exoticism and distance hidden in the landscape reappear and present themselves in the picturesque scenery.

Yu's landscape imaginary comprises unfrequented places, chaste ladies, and painting styles that merge Chinese and Western techniques and angles. These three elements thus interact with each other in an isomorphic structure, invoking a common natural ideal-an ethical, virginally pure, and essentialist model. The landscape that does not correspond to any of them is deemed "filthy" and unworthy of artists' attention.

\section{Conclusion}

To sum up, the scenery in Yu's travel writing of the 1930s assumes a twofold amalgamation and antinomy. On the one hand, it is both a result and a rejection of modern commercial society. Developing alongside the prosperity of modern vernacular Chinese, transportation, and tourism, these texts differ from traditional Chinese Youji and take on qualities of the German Baedeker guidebook genre. It viewed landscapes in an unprecedented way and created public space in the suburbs. Unlike Yu's early style, these works contain few political concerns or points of individual distress.

On the other, two major aesthetic patterns - the picturesque and feminized landscapeimply both Yu's global vision and lack a true sense of modern consciousness. While well educated in Western arts and literature, Yu absorbed more traditional Chinese influence at this stage of his career. His integrated aesthetics from Chinese and Western painting visons in his works occasionally presented an insurmountable artistic barrier to the public. The glaring stereotypes in Yu's feminized landscape confirm conventional sexual politics and objectify women as scenery. Such viewing patterns assume the readers and landscape viewers to be male intellectuals, endowed with a deep comprehension of Chinese and Occidental knowledge. All other people present in nature, such as Buddhist pilgrims, peasants, rickshaw drivers, tourists who are ignorant of Wang Wei's poems, and women, are merely part of the landscape. They are simply waiting to be discovered, gazed at, and framed in the picturesque scenery. This displays anxiety typical of the cultural hegemony: if everyone has the right to appreciate and actively engage in the landscape, the established landscape discourse will be challenged, and the space that male intellectuals have carved out will be threatened. In this sense, Yu's writing violates the original 
intention of the May Fourth Movement to develop the literature of common people (平民文學) and his promise of mass literature and art (大眾文藝) in 1928.

Intermingling creation and conservation, and oriental and occidental cultures, Yu's travel writing is a unique window into 1930s China; the amalgamation and clash it contains depict a segment of the complexity of modern Chinese literature.

\section{Declaration of Conflict of Interests}

The author(s) declared no potential conflicts of interest.

\section{Funding}

No funding has been received for the publication of this article. It is published free of any charge.

\section{Endnotes}

\footnotetext{
i Shanshui usually refers to the genres concerning nature, whereas the word Fengjing 風景 is used to translate "landscape." Tamaki (2017) analyzes the usage and etymology of the Chinese word Fengjing (pp. 13-49). On Shanshuipoems in medieval China, see Xiao (2018) and Obi (2014)'s work.

ii Controversially, Jackson (1984) proposed to understand the landscape from the field instead of documents, and he opposes interpreting it as a personal or private metaphor since the landscape should be a public and sharing space.

iii The key arguments and evidence in Wu's $(2012 ; 2017 ; 2018)$ three essays are similar. Wu recognizes a new mode of creation based on collaboration between writers and commerce, but continues to consider the aesthetics and discourses in Yu's early short stories and 1930s travelogues as a whole, omitting Yu's creative crises and the consequent shifts in Yu's literary pursuit during this period, which I will clarify in this paper.

iv Jiang (1996) has a detailed retrospection of Yu's travel writing from his Japanese period to his death and also mentions the cooperation between Yu and the bureau, while she confused Yu's journey to Hangjiang in 1933 with another one to Mount Tianmu in 1934.

${ }^{v}$ Oxford English Dictionary. (n.d.). Citation. In OED.com dictionary. Retrieved October 9, 2021, from https://www.oed.com

vi Comprehensive Chinese Word Dictionary. (n.d.). Citation. In Hanyudacidian.com dictionary. Retrieved October 9, 2021, from https://www.hanyudacidian.cn

vii For the debates on the definition of Youji as a genre, please see Wang (2008, pp. 6-30) and Hargett's (2018, pp. 4-6) discussion.

viii On the development of Youji in history, this paper mainly refers to Obi's (2014) and Hargett (2018)'s work.
} 
ix Yu writes to Du Heng, the editor of the journal Modernity, in a letter sent in 1933: "There isn't any way to get out of this situation. I'm afraid I'll have to offer you a blank exam paper for the upcoming issue because I'm unable to generate anything." (Yu, 2007, Vol. 6, p. 236) This letter reveals Yu's predicament at the moment. It is noticeable that just one month after this letter, Yu started his invited journey to Hangjiang and shifted his interest to travel literature.

${ }^{x}$ In this paper, when not alternately noted, translations from Chinese texts are by the author.

${ }^{x i}$ China Trave/ is a seminal publication in the field of Republican travel literature. It was created in 1927 by Chen Guangfu and has published numerous travelogues by prominent writers such as Yu Dafu, Zhang Henshui, Hu Shih, and others. For more information on its origins, see Zhu (1927).

xii Another example is Trave/ Notes along the Pingsui Railway (1935), which is also a Chinese Baedekerwith contributions from well-known writers such as Bing Xin, Gu Jiegang, Zheng Zhenduo. It was also an official trip organized by the director of Pingsui Railway Bureau, Shen Chang.

xiii Eggert's (2011) paper has further investigations on the authorship of the Baedeker.

xiv Hargett (2018) has also pointed out the personal features of Youji.

${ }^{x v}$ Yu's re-discovery of ancient Chinese texts is comparable to Fanon's (1986) practice in this regard. There is also a trajectory of his language conceptions in Black Skin, White Masks, from learning and admiring colonial language - French - to criticizing the admiration, and finally to reclaiming his cultural identity through repressed Black narratives and Black tones of speech.

xvi The Green Shanshui (Qing/v Shangshui) is a traditional landscape painting style, which mainly uses blue and green colors to depict natural scenes.

xvii Apart from the increased use of classical Chinese references, Yu incorporated more of his own classical poetry into his travelogues, whereas such poems were previously more private and appeared less frequently in Yu's vernacular creations (Hong, 2006). For instance, Diaotai de Chunzhou (1932) contains one of Yu's classical poems, Hangjiang Xiaoli Jicheng (1933) contains four, and Xiyou Rilu (1934) contains five.

xviii For investigations into the relationship of femme fatale and the phrase, see McLaren (1994, pp. 1-16). For other studies on Chinese fox-fairy stories, see Monschein (1988) and Huntington (2020).

xix This is a female figure in Bai Juyi's Pipa Xing 琵琶行 (AC 815). The woman was a renowned lute player in the capital. Years later, however, her beauty faded and she lost all her customers. She was eventually forced to lower herself and married a merchant from Xunyang.

${ }^{x x}$ For $Y u$, it seems self-evident that natural scenery will cure physical illness. Whether living in Japan or China, Yu sought healing in nature. This expectation is also frequently rendered in his fiction.

xxi For example, he attributed corruption and the failure of political faculties to officials' ignorance of nature. See: The Appreciation on Shanshui and Natural Scenery, 山水及自然景物的欣賞, Yu, Vol. 11, pp. 227-232.

\section{References}

Andrews, M. (1999). Landscape and western art. Oxford University Press.

Edward Mendelson. (1985). Baedeker's Universe. Yale Review, Spring (74), 386-403. 
Eggert, P. (2015). Discourse Versus Authorship. In P. Cohen (Ed.), Texts and textuality textual instability, theory, and interpretation (pp. 207-234). Routledge.

Fanon, F. (1986). Black Skin, White Masks. Pluto Press.

Freud, S. (2001). A Special Type of Choice of Object Made by Men, On the Universal Tendency of Debasement in the Sphere of Love. In J. Strachey, A. Freud, A. Strachey, \& A. Tyson (Eds.), The standard edition of the complete psychological works of Sigmund Freud (pp. 165-190). Hogarth Press.

Hangjiang Railway Bureau (Ed.). (1933). 浙東景物紀 [The scene in the east of Zhengjiang].

Hargett, J. M. (2018). Jade mountains et cinnabar pools: the history of travel literature in imperial China. University of Washington Press.

Hong, J.Y. (2006). 郁達夫文類選擇及其文學理想 [Yu Dafu Wenlei Xuanze Jiqi Wenxue Lixiang] In H. Li, J. Chen, \& L. Chen (Eds.), Zhongwai Yu Dafu yanjiu wenxuan (pp. 677-705). Zhejiang University Press.

Huntington, R. (2020). Alien Kind: Foxes and Late Imperial Chinese Narrative. Brill.

Jackson, J. B. (1984). Discovering the vernacular landscape. Yale University Press.

Jia, H.Y. (2005). Zhongguo Youji wenxian yanjiu [中國遊記文獻研究]. Southeast University Press.

Jiang, J.N. (1996). 江湖之憂更潚灑——論郁達夫及其紀遊文學 [Jianghu Zhi You Geng Xiaosa: Lun Yu Dafu Jiqi Jiyou Wenxue]. Modern Chinese Literature Studies, (04), 133-147.

Karatani, K. (1993). Origins of modern Japanese literature. (B. de Bary, Trans.). Duke University Press.

Levan, V. (2012). The Meaning of Foreign Text in Yu Dafu's "Sinking" Collection. Modern Chinese Literature and Culture, 24(1), 48-87.

Lee, L. O. (2006). 引來的浪漫主義:重讀郁達夫《沉淪》中的三篇小說 [Romanticism Introduced: Three Short Stories in Yu Dafu Sinking Revisited]. Journal of Jiangsu University (Social Science Edition) (01),1-9.

Lu, Xun. (2005). 我之節烈觀 [My Views on Chastity]. In Complete Works of Lu Xun, People's Literature Publishing House, (pp. 121-33). (Originally published in 1918).

McLaren, A. E. (1994). The Chinese Femme Fatale: Stories from the Ming Period. Wild Peony.

Mitchell, W. J. T. (2002). Landscape and power (2nd ed.). University of Chicago Press.

Monschein, Y. (1988). Der Zauber der Fuchsfee: Entstehung und Wandel eines "Femme-fatale"-Motivs in der chinesischen Literatur. Haag + Herchen.

Nakazatomi, S. (2017). 作為文體的風景: 中國古代白話小說“風景之發現“之前的敘景 [Zuowei Wenti de Fengjing: Zhongguo Gudai Baihua Xiaoshuo "Fengjing Zhi Faxian" Zhiqian de Xujing]. Journal of Sun Yat-Sen University, (02), 13-21.

Obi, K. (2014). Nature and the Views of Nature Expressed in Chinese Literature (Yiping Shao, Trans.). Shanghai Classics Publishing House.

Pingsui Railway Bureau (Ed.). (1935). 平綏沿線旅行記 [Travel Notes along the Pingsui Railway].

Sullivan, M. (2008). The arts of China (5th ed.). University of California Press. 
Tamaki, O. (2017). The Meaning of The Landscape. In R. Tan, Z. Chen, \& G. Liang (Trans.), Lun Zhongguo shi. (pp. 3-32). Guizhou People's Press.

Tian, X. (2012). Visionary journeys: Travel writings from early medieval and nineteenth-century China. Harvard University Asia Center.

Wang, J.F. 王佳帆. (2021). 《孤獨的收割者》對《沉淪》寫作策略的影響——郁達夫文論為參照 [Influence of "The Solitary Reaper" on the Writing Strategy of "Drowned": A Perspective from Literary Theory of Yu Dafu]. Journal of Modern Chinese Literature, (03),43-51.

Wang，L.Q. (2008). 中國古代山水遊記研究 (修訂版) [A Study of Landscape Travel Accounts from China's Ancient Eras (Revised Edition)]. China Social Sciences Press.

Wordsworth, W. (1993). Wordsworth's guide to the lakes: the fifth edition (1835). Oxford University Press.

Wu, X.D. (2012). 郁達夫與中國現代“風景的發現" [Yu Dafu Yu Zhongguo Xiandai "Fengjing de Faxian"]. Modern Chinese Literature Studies, (10), 80-89.

. (2017). 郁達夫與現代風景的發現問題 [Yu Dafu Yu Zhongguo Xiandai Fengjing de FaxianWenti]. Journal of Modern Chinese Studies, 02, 4-13.

. (2010, July 21). 擬像的風景 [The Landscape of Simulacrum]. China Reading Weekly, 013.

Xiao, C. (2018). 詩與它的山河 [Shi yu ta de shanhe]. SDX Joint Press.

Xu，Z.J. (2009). 他者及其性政治敘事策略——論郁達夫的女性書寫[The Other and the Narrative Strategy of Sexual Politics: On Yu Dafu's Female Writing]. Literary Review, 05, 33-38.

Yu, D.F. (2007). 郁達夫全集 [The Complete Works of Yu Dafu] (Vols. 1-12). Zhejiang University Press.

Zhao, J.H. (1936). 編輯十年記 [Notes on the Tenth Anniversary]. China Travel, 10(1), 198.

Zhao, Y. X. (2017). A Preliminary Study on the Literature of Guidebooks in Republican China (thesis). Tianjin Normal University.

Zhu, C. Z. (1927). 旅行部緣起 [The Origin of Travel Department]. China Travel, 1, 3.

Yidan Wang is a graduate student in Critical Asian Humanities at Duke University. She earned an MA in comparative literature and a BA in Chinese literature from Fudan University. Her research interests include twentieth-century Chinese literature, travel writing, postcolonial theory, and $\mathrm{Yu}$ Dafu studies. Her current project focuses on Yu Dafu's ideal of language and its interaction with colonial hierarchy, leftist discourse, and classical resources. 